\title{
A Sesquiterpene Synthase from the Endophytic Fungus Serendipita indica Catalyzes Formation of Viridiflorol
}

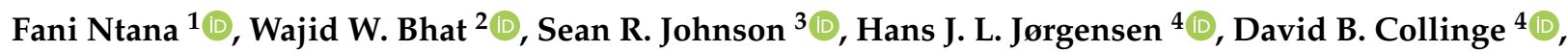 \\ Birgit Jensen ${ }^{4}\left(\mathbb{D}\right.$ and Björn Hamberger ${ }^{2, *}$ \\ 1 Department of Environmental Science, Aarhus University, Frederiksborgvej 399, 4000 Roskilde, Denmark; \\ fntana@envs.au.dk \\ 2 Department of Biochemistry and Molecular Biology, Michigan State University, 603 Wilson Rd, \\ East Lansing, MI 48824, USA; bhatwaji@msu.edu \\ 3 New England Biolabs, Inc., 240 County Road, Ipswich, MA 01938, USA; sjohnson@neb.com \\ 4 Department of Plant and Environmental Sciences and Copenhagen Plant Science Centre, \\ University of Copenhagen, Thorvaldsensvej 40, 1871 Copenhagen, Denmark; hjo@plen.ku.dk (H.J.L.J.); \\ dbc@plen.ku.dk (D.B.C.); bje@plen.ku.dk (B.J.) \\ * Correspondence: hamberge@msu.edu
}

Citation: Ntana, F.; Bhat, W.W.; Johnson, S.R.; Jørgensen, H.J.L.; Collinge, D.B.; Jensen, B.; Hamberger, B. A Sesquiterpene Synthase from the Endophytic Fungus Serendipita indica Catalyzes Formation of Viridiflorol. Biomolecules 2021, 11, 898. https:/ / doi.org/10.3390/biom11060898

Academic Editor: Nurhayat Tabanca

Received: 20 May 2021

Accepted: 12 June 2021

Published: 16 June 2021

Publisher's Note: MDPI stays neutral with regard to jurisdictional claims in published maps and institutional affiliations.

Copyright: (c) 2021 by the authors. Licensee MDPI, Basel, Switzerland. This article is an open access article distributed under the terms and conditions of the Creative Commons Attribution (CC BY) license (https:// creativecommons.org/licenses/by/ $4.0 /)$.

\begin{abstract}
Interactions between plant-associated fungi and their hosts are characterized by a continuous crosstalk of chemical molecules. Specialized metabolites are often produced during these associations and play important roles in the symbiosis between the plant and the fungus, as well as in the establishment of additional interactions between the symbionts and other organisms present in the niche. Serendipita indica, a root endophytic fungus from the phylum Basidiomycota, is able to colonize a wide range of plant species, conferring many benefits to its hosts. The genome of S. indica possesses only few genes predicted to be involved in specialized metabolite biosynthesis, including a putative terpenoid synthase gene (SiTPS). In our experimental setup, SiTPS expression was upregulated when the fungus colonized tomato roots compared to its expression in fungal biomass growing on synthetic medium. Heterologous expression of SiTPS in Escherichia coli showed that the produced protein catalyzes the synthesis of a few sesquiterpenoids, with the alcohol viridiflorol being the main product. To investigate the role of SiTPS in the plant-endophyte interaction, an SiTPS-over-expressing mutant line was created and assessed for its ability to colonize tomato roots. Although overexpression of SiTPS did not lead to improved fungal colonization ability, an in vitro growth-inhibition assay showed that viridiflorol has antifungal properties. Addition of viridiflorol to the culture medium inhibited the germination of spores from a phytopathogenic fungus, indicating that SiTPS and its products could provide $S$. indica with a competitive advantage over other plant-associated fungi during root colonization.
\end{abstract}

Keywords: antifungal; Basidiomycota; endophyte; Piriformospora indica; sesquiterpenoid; terpene synthase; viridiflorol

\section{Introduction}

Apart from their role in the general metabolism, terpenoids comprise a large and structurally diverse group of specialized metabolites. Several terpenoids produced by plants, bacteria or fungi are of value to the pharmaceutical, cosmetic and food industries, while in nature these compounds mainly serve as defense and signaling molecules [1]. Fungi, with an estimated diversity of more than five million species [2], are considered to be a massive, yet untapped source of terpenoids. Biosynthesis of fungal terpenoids has been described more systematically in the phylum Ascomycota (representing around 60\% of the described fungal species), while metabolic pathways in basidiomycete fungi (including mushroom-forming fungi) remain obscure. However, constant progress in genome sequencing and comparative annotation is shedding light on the terpenoid biosynthetic mechanisms used by basidiomycetes [3]. 
Sesquiterpenoid (C15) biosynthesis in Basidiomycota has received increasing attention over the last decade [4-8]. The specific compounds are characterized by rare structures, unusually enhanced antibiotic and cytotoxic activity [9]. The first committed step in their biosynthesis is the formation of the terpenoid scaffold by the cyclization of the linear precursor farnesyl diphosphate (E,E-FPP, C15), a reaction catalyzed by enzymes termed sesquiterpene synthases (STSs) [10]. Initially, STSs cleave off the diphosphate moiety from $E, E-F P P$, forming a reactive carbocation, which undergoes a series of cyclizations and rearrangements. These enzymes stabilize the carbocation intermediates, until the cascade is terminated by proton abstraction, or quenching by water. Alternatively, STSs can use a secondary carbocation, formed from an E,E-FPP isomer, the (3R)-nerolidyl diphosphate $(3 R-\mathrm{NPP})$, and then proceed to the formation of the terpenoid skeleton (Figure 1).

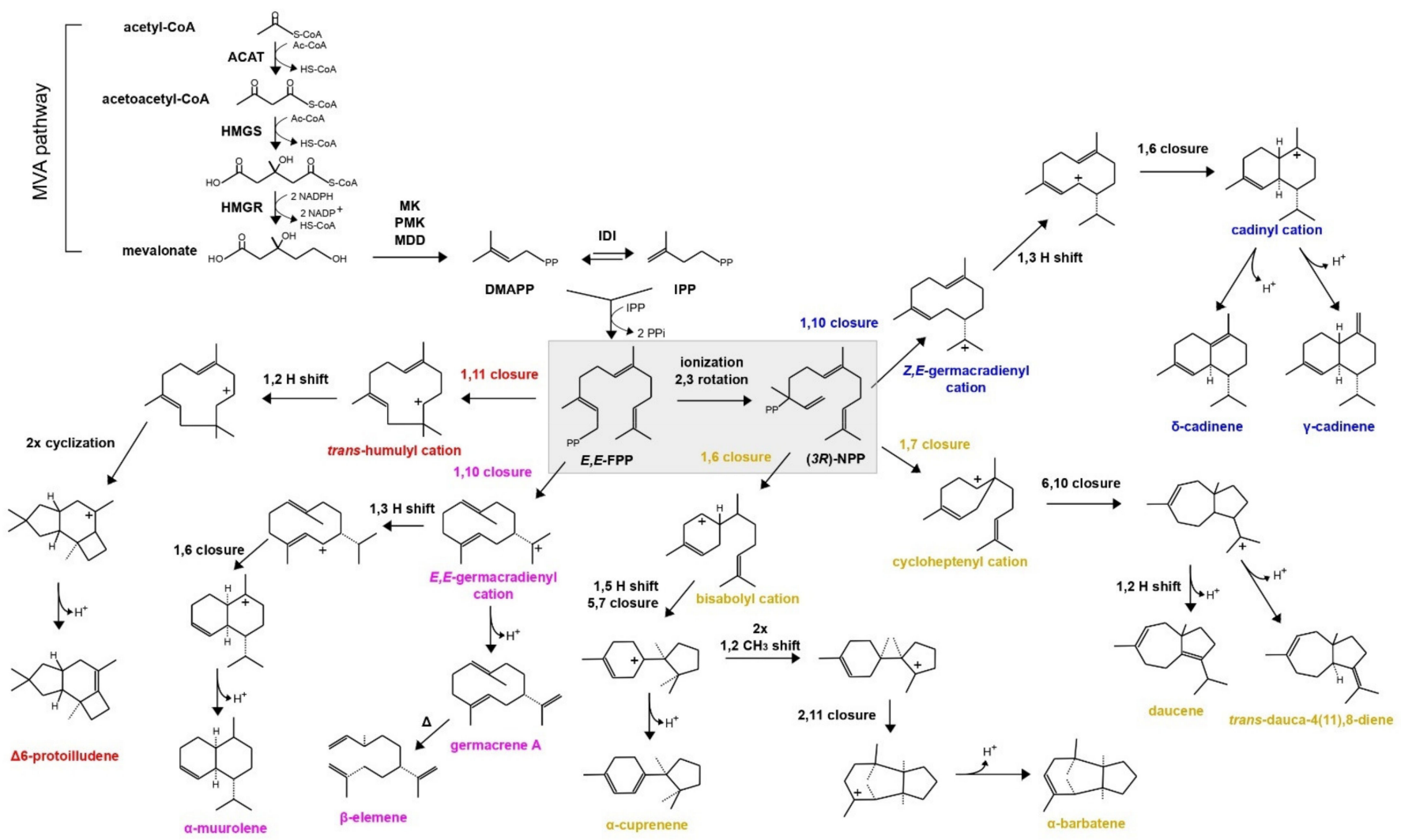

Figure 1. Proposed biosynthetic pathways of several sesquiterpenes found in basidiomycete fungi. Sesquiterpenoid scaffolds (and the respective STSs) can be distinguished by the first cyclization step of E,E-FPP or (3R)-NPP. Here, four distinct structural groups are presented in different colors, each one containing terpenoids formed by different types of STSs. Terpenoids derived from 1,10 closure of E,E-FPP are shown in pink (STS Clade I), 1,11 closure of E,E-FPP are shown in red (STS Clade III), 1,6 or 1,7 closure of (3R)-NPP are shown in yellow (STS Clade IV) and 1,10 closure of (3R)-NPP are shown in blue (STS Clade II) (adapted from [3]).

Interestingly, a comprehensive phylogenetic analysis of all available basidiomycete STSs showed that these enzymes are grouped in phylogenetic clades (phylogenetic clusters), not only according to sequence similarity, but also based on their cyclization mechanism [11]. In detail, all the enzymes of each phylogenetic clade (Figure 2) catalyze the same first carbon-carbon $(\mathrm{C}-\mathrm{C})$ bond forming reaction (e.g., Clade II enzymes perform 1,10 cyclization of (3R)-NPP) (Figure 1) [3]. This means that a simple phylogenetic analysis can offer a predictive framework for targeted discovery of sesquiterpenoids with a specific skeleton [11]. 


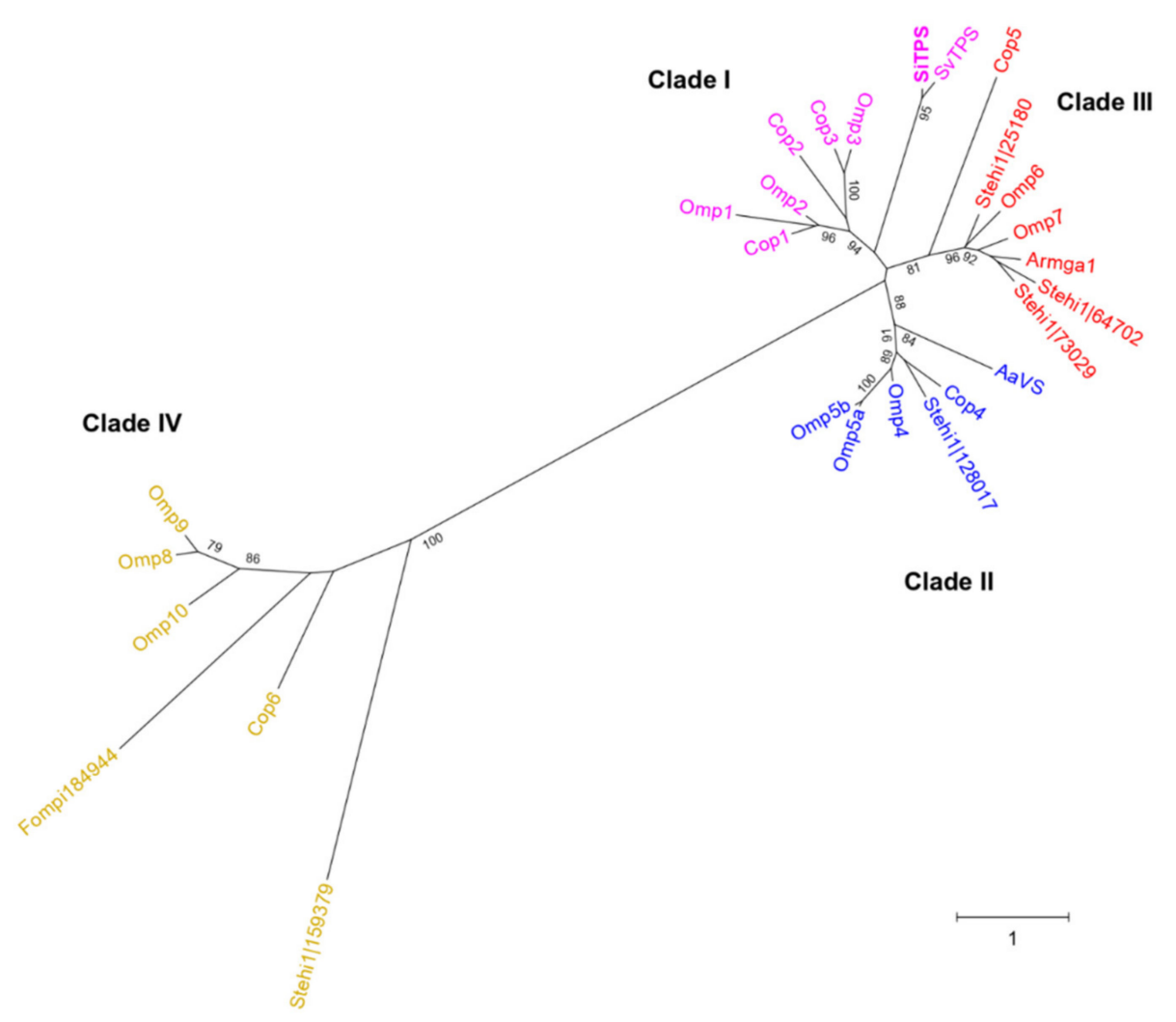

Figure 2. Phylogenetic analysis of selected functionally characterized basidiomycete STSs, Cop16 [4,6] from Coprinopsis cinerea, Omp1-10 from Omphalotus olearius, Fompi I 84944 from Fomitopsis pinicola [3], Stehi1 I 159379, 128017, 25180, 64702, 73029 [8,12] from Stereum hirsutum, ArmGa1 [13] from Armillaria gallica, AaVS [14] from Cyclocybe aegerita (syn. Agrocybe aegerita), SiTPS from Serendipita indica and the SvTPS (NCBI accession number: PVF97777.1) from Serendipita vermifera were included in the analysis. A maximum-likelihood tree shows the 4 different STS clades formed, described also in $[3,15]$ and Figure 1 . The enzymes falling in one clade are considered to catalyze the first cyclization of the substrate in the same specific way; STS Clade I catalyze 1,10 cyclization of E,E-FPP (pink); Clade II, 1,10 cyclization of (3R)-NPP (blue); Clade III, 1,11 cyclization of E,E-FPP (red); Clade IV, 1,6 or 1,7 cyclization of (3R)-NPP (yellow). SiTPS is found in Clade I. The scale bar indicates a genetic distance of 1 and the bootstrap values are shown below the branches.

S. indica (formerly known as Piriformospora indica) is an endophytic fungus, belonging to the phylum Basidiomycota and extensively used in plant-fungal interaction studies [16-18]. The endophyte can successfully colonize several plant species as a root mutualist [19], conferring several benefits to the host plant, including increased plant biomass [20-23], and improved plant resistance against biotic [24-27] and abiotic challenges $[20,28,29]$. S. indica has a characteristic biphasic colonization style, during which a transition from an initial biotrophic growth to a later plant cell-death associated phase is observed [26]. To colonize plant roots successfully, S. indica suppresses host immune responses by secreting effectors and interfering with the plant hormone biosynthesis and signaling $[26,30,31]$. In addition, the endophyte is able to produce phytohormone analogues that contribute further to the establishment of the mutualistic interaction with the host $[32,33]$. Colonization by S. indica was also shown to stimulate host specialized metabolism in several plants [34-36], but until now there has been no evidence that this endophytic fungus can itself produce any type of specialized metabolite. In fact, sequencing of the $S$. indica genome showed that the endophyte lacks the large repertoire of terpenoid biosynthetic genes that characterize other basidiomycetes [9].

Here, we describe the discovery and the functional characterization of a terpene synthase gene (SiTPS), found in the genome of S. indica. A comparative phylogenetic 
analysis showed that SiTPS belongs to Clade I of STSs, together with enzymes that catalyze 1-10 cyclization of E,E-FPP. Functional characterization in in vitro and in vivo Escherichia coli expression systems showed that SiTPS synthesizes a couple of sesquiterpenes, with viridiflorol, a sesquiterpene alcohol, being the main product. Since it was not shown previously that $S$. indica has the potential to produce terpenoids, we explored the role of SiTPS and its products in the interaction with the host plant and other fungal competitors. We generated an SiTPS-overexpressing transgenic S. indica line and compared it to a control strain and the wild type $S$. indica with respect to its ability to colonize tomato seedlings. In addition, we performed a growth assay, where spores from the phytopathogenic fungus Colletotrichum truncatum were used to inoculate culturing media containing viridiflorol. Overexpression of SiTPS did not lead to enhanced colonization ability but the growth assay showed that viridiflorol can inhibit spore germination, indicating that SiTPS could be involved in a $S$. indica defense mechanism. Unravelling the role of SiTPS and the produced compounds during the association between $S$. indica, tomato plants and other plant-associated fungi may provide insights into the role of microbial terpenoids during plant-fungal, fungal-fungal and the tripartite interaction.

\section{Materials and Methods}

\subsection{Fungal and Plant Material}

S. indica (isolate DSM11827) was grown at $28^{\circ} \mathrm{C}$ in liquid complete medium (CM) [37], supplemented with $2 \%$ glucose $(w / v)$ on a shaker at $150 \mathrm{rpm}$, or on solid CM plates, supplemented with $2 \%$ glucose $(w / v)$ and $1.5 \%(w / v)$ agar.

Tomato seeds (Solanum lycopersicum, cv. Moneymaker) were surface sterilized with $70 \%$ ethanol for $1 \mathrm{~min}, 1 \% \mathrm{NaClO}(\mathrm{v} / \mathrm{v})$ for $10 \mathrm{~min}$ and rinsed with sterile MilliQ water. The seeds were kept on sterile filter paper in a growth chamber $\left(12 \mathrm{~h}\right.$ day $22{ }^{\circ} \mathrm{C} / 12 \mathrm{~h}$ night $18{ }^{\circ} \mathrm{C}, 120 \mu \mathrm{E} / \mathrm{m}^{2} \mathrm{~s}$ light intensity, $60 \%$ relative humidity) until fully germinated (11 days). Plant root inoculation with $S$. indica wild type and mutants was performed by incubating the tomato seedlings in $40 \mathrm{~mL}$ of fungal inoculum $(300,000$ chlamydospores $/ \mathrm{mL})$ overnight, on a shaker $(120 \mathrm{rpm})$ at room temperature. For the control treatment, sterile water was used instead of the fungal chlamydospore suspension. After inoculation, the seedlings were sown on Murashige-Skoog (MS) Basal medium (Sigma-Aldrich, St. Louis, MO, USA), supplemented with $1.5 \%(w / v)$ agar and grown in the same growth chamber until harvest.

\subsection{Discovery of SiTPS and Phylogenetic Analysis of a Putative Terpene Synthase}

The genome of S. indica (available at Joint Genome Institute-JGI, https:/ / genome.jgi. doe.gov/Pirin1/Pirin1.home.html; accessed on 15 June 2021) possesses one gene (JGI mRNA:PIIN_06735, called SiTPS from now on) annotated as member of the terpene synthase $C$ family (enzymes that synthesize terpenes of the general and specialized metabolism). The predicted amino acid sequence of SiTPS (JGI Protein Id: 77541) was aligned with Basidiomycota STSs, including the functionally characterized Coprinopsis cinerea (Cop1-6) [4-6] and Omphalotus olearius TPSs (Omp1-10) [3], using the online tool GUIDANCE2 Server (http://guidance.tau.ac.il/ver2/; accessed on 15 June 2021) and the multiple sequence alignment (MSA) algorithm CLUSTALW. A Maximum-likelihood phylogenetic tree was constructed in MEGAX [38] (bootstrap of 500) using the default settings (Figure 2).

The SiTPS sequence was also used in a BLASTp search (https:/ / blast.ncbi.nlm.nih. gov / Blast.cgi; accessed on 15 June 2021) in order to identify similar proteins and investigate its functional context. A selection of proteins (threshold of E-value 2e-67) together with all the putative TPSs from other Serendipita species was aligned with SiTPS using again GUIDANCE2 (http:/ / guidance.tau.ac.il/ver2/; accessed on 15 June 2021) (MSA algorithm MAFFT). The alignment file was imported in MEGAX [38] and a maximumlikelihood phylogenetic tree (bootstrap of 500) was constructed using the default settings (Supplementary Figure S1). 
The genomes of $S$. indica and $S$. vermifera were mined for specialized metabolism related genes by performing an antibiotics and Secondary Metabolites Analysis SHell (antiSMASH-fungal version) using the default settings (Supplementary Figure S2) [39].

\subsection{SiTPS Expression in Planta and In Vitro}

Tomato seedlings were harvested at $11 \mathrm{dpi}$ (days post inoculation) and roots from seven plants were pooled together in each replication. Before RNA extraction, the samples were freeze-dried overnight. Fungal biomass from mature $S$. indica cultures, grown for two weeks on CM agar plates, was also harvested. Total RNA from root and fungal samples was extracted using the Spectrum ${ }^{\mathrm{TM}}$ Plant Total RNA Kit (Sigma-Aldrich, St. Louis, MO, USA) and its integrity was validated with an agarose gel $1 \%(w / v)$. For the plant root samples $1.5 \mu \mathrm{g}$ of total RNA was used to synthesize cDNA, while for the fungal samples, cDNA was synthesized using $250 \mathrm{ng}$ total RNA. cDNA synthesis for root and fungal samples was performed with the Revert First Strand cDNA Synthesis kit and an oligo-dT primer (Thermo Fisher Scientific, Waltham, MA, USA) with a final volume of $20 \mu \mathrm{L}$.

For the RT-qPCR, $2 \mu \mathrm{L}$ of $1 / 10$ diluted cDNA were used as a template in a $10 \mu \mathrm{L}$ reaction, using $5 \mu \mathrm{L}$ of the Brilliant III Ultra-Fast SYBR ${ }^{\circledR}$ Green (Agilent Technologies, Santa Clara, CA, USA) and SiTPS-specific primers (Supplementary Table S1). Each RTqPCR reaction was performed with three technical replications for the four biological replications. RT-qPCR was performed using the AriaMx Real-Time PCR System-G8830A (Agilent Technologies, USA), with a program of $95^{\circ} \mathrm{C}$ for $5 \mathrm{~min}$, followed by 40 cycles of $95^{\circ} \mathrm{C}$ for $30 \mathrm{~s}, 60^{\circ} \mathrm{C}$ for $1 \mathrm{~min}$ and $72{ }^{\circ} \mathrm{C}$ for $1 \mathrm{~min}$. A final dissociation step was performed to assess the quality of amplified products and the specificity of the primers. Expression of SiTPS was normalized using S. indica glyceraldehyde-3-phosphate dehydrogenase gene (GAPDH, GenBank: FJ810523.1) expression levels and calculated with the $2^{-\Delta \mathrm{Ct}}$ method $[40,41]$.

\subsection{Heterologous Expression in E. coli and In Vitro Characterization of SiTPS}

The coding region of SiTPS (PIIN_06735) was amplified from S. indica cDNA (Supplementary Table S1) and cloned in-frame with a His-tag (C-terminal) into the NcoI digested pET28b+ vector (Novagen), using the In-Fusion ${ }^{\circledR}$ HD Cloning Kit (Takara Bio,Kusatsu, Japan), according to the manufacturer's instructions. The resulting plasmid pET_SiTPS was transformed into E. coli C41 OverExpress ${ }^{\mathrm{TM}}$ cells (Lucigen, Middleton, WI, USA). Heterologous expression and protein purification was performed as described in [42]. Briefly, $500 \mu \mathrm{L}$ of an overnight culture ( $5 \mathrm{~mL}$ LB broth containing $50 \mu \mathrm{g} / \mathrm{mL}$ kanamycin) was used to inoculate $50 \mathrm{~mL}$ of production medium (Terrific Broth medium ( $\mathrm{pH} \mathrm{7.0),} \mathrm{containing}$ $50 \mu \mathrm{g} / \mathrm{mL}$ kanamycin). Cultures were grown at $37^{\circ} \mathrm{C}$ in a shaking incubator $(180 \mathrm{rpm})$. When culture $\mathrm{OD}_{600}$ reached $0.6,100 \mu \mathrm{L}$ of IPTG (Isopropyl $\beta$-D-1-thiogalactopyranoside, $0.2 \mathrm{mM}$ ) were added to induce expression. Protein expression proceeded overnight at $16^{\circ} \mathrm{C}$ in a shaking incubator (180 rpm). The following day, cells were harvested by centrifugation (4500 rpm) at $4^{\circ} \mathrm{C}$ for $20 \mathrm{~min}$ and lysed using the CelLytic B Cell Lysis Reagent (Sigma-Aldrich, St. Louis, MO, USA), supplemented with $0.1 \mathrm{mg} / \mathrm{mL}$ lysozyme, $10 \mu \mathrm{L} / \mathrm{mL}$ protease inhibitor cocktail (Sigma-Aldrich, St. Louis, MO, USA), $0.2 \mathrm{mg} / \mathrm{mL}$ benzoase, 25 $\mathrm{mM}$ imidazole, $500 \mathrm{mM} \mathrm{NaCl}$ and $5 \%(v / v)$ glycerol. The cell lysate was further used for protein purification, using the His SpinTrap Kit (GE Healthcare, Chicago, IL, USA). Proteins were desalted with the PD MiniTrap G-25 desalting columns (GE Healthcare, Chicago, IL, USA) according to the manufacturer's instructions and eluted with $600 \mu \mathrm{L}$ desalting buffer (20 mM HEPES (pH 7.2), 1 mM MgCl $2,350 \mathrm{mM} \mathrm{NaCl}, 5 \mathrm{mM} \mathrm{DTT}$, and 5\% (v/v) glycerol).

The in vitro terpene synthase assay was performed in a $500 \mu \mathrm{L}$ reaction that contained $5 \mu \mathrm{g}$ substrate (GPP, E,E-FPP or GGPP (Cayman Chemicals, Ann Arbor, MI, USA)), $100 \mu \mathrm{g}$ purified enzyme, $10 \mathrm{mM} \mathrm{MgCl}_{2}, 100 \mathrm{mM} \mathrm{KCl}, 5 \mathrm{mM}$ DTT and $10 \%$ v/v glycerol in $50 \mathrm{mM}$ HEPES (pH 7.2). The reaction was overlaid with $500 \mu \mathrm{L}$ n-hexane. Reactions were carried out at $30^{\circ} \mathrm{C}$ for $1 \mathrm{~h}$, followed by vortexing to extract the products into the organic phase. Layers were separated by centrifugation and hexane was removed for GC-MS analysis. 


\subsection{In Vivo Characterization of SiTPS}

The in vivo system was established by modifying the previously developed diterpene production system [43]. The GGPP synthase gene was removed from the pGG vector [44] and replaced by a Gallus gallus FPP synthase gene (FPPS-Genbank XM_01529864). In detail, the G. gallus FPPS was synthesized (Integrated DNA Technologies, Coralville, IA, USA) and cloned into NdeI and XhoI digested pACYCDuet vector (Novagen), using the In-Fusion ${ }^{\circledR}$ HD Cloning Kit (Takara Bio, Kusatsu, Japan). The resulting plasmid pACYCDuet_GgFFPS, together with pIRS, a plasmid containing three upstream genes of the MEP pathway [43], was introduced to E. coli C41 OverExpress ${ }^{\mathrm{TM}}$ cells (Lucigen, Middleton, WI, USA) to create a farnesyl diphosphate-producing strain. Transformed E. coli cells were grown on LB agar plates containing kanamycin $(25 \mu \mathrm{g} / \mathrm{mL})$, chloramphenicol $(20 \mu \mathrm{g} / \mathrm{mL})$, and streptomycin $(25 \mu \mathrm{g} / \mathrm{mL})$ and were verified by colony PCR. A single PCR-positive clone was grown in $50 \mathrm{~mL}$ Terrific Broth medium ( $\mathrm{pH} 7.0$ ), with the appropriate antibiotics at $37^{\circ} \mathrm{C}$ until the culture reached an $\mathrm{OD}_{600}$ of 0.6 . The temperature was lowered to $16^{\circ} \mathrm{C}$ for $1 \mathrm{~h}$ before expression was induced with $1 \mathrm{mM}$ IPTG. The culture was also supplemented with $40 \mathrm{mM}$ pyruvate, $1 \mathrm{mM} \mathrm{MgCl} 2$ and was grown for an additional $72 \mathrm{~h}$. Cell pellets were extracted in $50 \mathrm{~mL}$ of n-hexane, the organic phase was concentrated under $\mathrm{N}_{2}$ and analyzed by GC-MS.

\subsection{Gas Chromatography-Mass Spectrometry (GC-MS) Analysis}

GC-MS analysis was performed as described by [45] on an Agilent 7890A GC with an Agilent VF-5ms column ( $30 \mathrm{~m} \times 250 \mu \mathrm{m} \times 0.25 \mu \mathrm{m}$, with $10 \mathrm{~m}$ EZ-Guard) and an Agilent $5975 \mathrm{C}$ detector. The inlet was set to $250{ }^{\circ} \mathrm{C}$ splitless injection of $1 \mu \mathrm{L}$ helium carrier gas with a column flow of $1 \mathrm{~mL} / \mathrm{min}$. The detector was activated after a three-minute solvent delay. The oven temperature ramp started at $80^{\circ} \mathrm{C}$ and held for $1 \mathrm{~min}$, then increased to $130{ }^{\circ} \mathrm{C}$ by $40{ }^{\circ} \mathrm{C} / \mathrm{min}$, increased to $250^{\circ} \mathrm{C}$ by $10^{\circ} \mathrm{C} / \mathrm{min}$, following by a final increase of $100{ }^{\circ} \mathrm{C} / \mathrm{min}$ to $325^{\circ} \mathrm{C}$, where it was held for $3 \mathrm{~min}$. Obtained spectra were compared with NIST17 Mass Spectral Database. Analytical standards of viridiflorol (CAS 552-02-3) and ledol (CAS 577-27-5) were purchased from Sigma Aldrich (Cat No. 72999-10MG) and Santa Cruz (Cat No. sc-396548), respectively.

\subsection{Construction of Overexpression Plasmids and S. indica Peg-Mediated Transformation}

For creating a SiTPS-overexpressing mutant, the SiTPS coding sequence was cloned into a NheI and PmeI digested K167 vector, a S. indica-compatible vector developed in the Zuccaro lab (S. Wawra and H. Widmer, unpublished; modified from [46]) using the InFusion ${ }^{\circledR}$ HD Cloning Kit (Takara Bio, Kusatsu, Japan). The resulting plasmid K167_SiTPSov carried the SiTPS coding sequence under the control of a strong promoter (FGB1 promoterFungal Glucan-Binding 1, PIIN_03211) (Supplementary Figure S4). The empty vector named K167_ev was transformed as control.

S. indica protoplasts were isolated and transformed with K167_SiTPSov and K167_ev through polyethylene glycol (PEG)-mediated transformation according to [47]. Young mycelium from a 7-day-old S. indica culture was harvested, homogenized and left to regenerate for three further days. The regenerated mycelium was treated with $20 \mathrm{~mL}$ SMC solution (1.33 M sorbitol, $50 \mathrm{mM} \mathrm{CaCl}_{2}$ and $20 \mathrm{mM} \mathrm{MES}$ ) containing $0.02 \mathrm{~g} / \mathrm{mL}$ lysing enzyme from Trichoderma harzianum (Sigma-Aldrich, St. Louis, MO, USA) at $32{ }^{\circ} \mathrm{C}$. After $2 \mathrm{~h}$, protoplasts were harvested and transformed with 7-10 $\mu \mathrm{g}$ linearized and purified plasmid in the presence of $40 \%$ PEG 3350 and heparin $(15 \mathrm{mg} / \mathrm{mL})$. Protoplast were regenerated on plates with two layers of malt yeast peptone (MYP) agar supplemented with $0.3 \mathrm{M}$ sucrose $(0.7 \% w / v$ malt extract, $0.1 \% w / v$ peptone, $0.05 \% w / v$ yeast extract). The bottom medium contained $1.2 \%$ agar and hygromycin B $(80 \mu \mathrm{g} / \mathrm{mL})$. The top medium $(0.6 \%$ agar and no antibiotics) was mixed with the transformation mixture and then quickly poured on to the solidified bottom medium. The plates were incubated at $28^{\circ} \mathrm{C}$. After $10-14$ days, regenerated colonies were transferred to CM plates supplemented with $80 \mu \mathrm{g} / \mathrm{mL}$ hygromycin B and verified for carrying either K167_SiTPS or K167_EV. S. indica mutants that were not 
impaired in growth and with the right mating type were selected and used for further experiments (Supplementary Figure S5).

\subsection{Quantification of Root Colonization by S. indica and Mutants with $q P C R$}

Genomic DNA was extracted from root samples of inoculated tomato plants at 2 and 11 dpi using the DNeasy ${ }^{\circledR}$ Plant Mini Kit (Qiagen, Hilden, Germany). Roots from eight plants were pooled in one replication and three replications were included per time-point and treatment. The qPCR was performed in the AriaMx Real-Time PCR System-G8830A (Agilent Technologies, Santa Clara, CA, USA) using a cycling program of $95^{\circ} \mathrm{C}$ for $5 \mathrm{~min}$, 30 cycles of $95{ }^{\circ} \mathrm{C}$ for $30 \mathrm{~s}, 62{ }^{\circ} \mathrm{C}$ for $1 \mathrm{~min}$, and $72{ }^{\circ} \mathrm{C}$ for $1 \mathrm{~min}$. A final dissociation step was performed to assess the quality of amplified products and the specificity of the primers. In a $10 \mu \mathrm{L}$ reaction, $5 \mu \mathrm{L}$ Brilliant III Ultra-Fast SYBR ${ }^{\circledR}$ Green (Agilent Technologies, Santa Clara, CA, USA), $1 \mu \mathrm{L}$ of total DNA (30-50 ng $/ \mu \mathrm{L}$ ) and $0.4 \mu \mathrm{M}$ of plant- or fungus-specific primers were used (Supplementary Table S1).

Fungal colonization was determined using the ratio of fungal to plant DNA. For the quantification of fungal DNA, a standard curve was generated using serial dilutions of DNA from a pure $S$. indica culture and specific primers for the Internal Transcribed Spacer-ITS (SiITS, GenBank: NR_119580.1, S. indica wt: $y=-3.2357 x+7.599$ and $\mathrm{R}^{2}=0.9969$, S. indica evV: $y=-3.3687 x+9.3553$ and $R^{2}=0.9942$, S. indica ovII: $y=-3.3667 x+10.845$ and $\left.R^{2}=0.9954\right)$. Plant DNA was quantified similarly, using a standard curve of plant DNA dilutions and specific primers for S. lycopersicum $\beta$-tubulin gene (SITUB, GenBank: DQ205342.1) $\left(y=-3.3527 x+16.513\right.$ and $\left.R^{2}=0.999\right)$.

\subsection{Testing the Antimicrobial Activity of Viridiflorol}

The antifungal activity of viridiflorol was determined using a growth assay, where the plant pathogenic fungus $C$. truncatum (syn. Colletotrichum capsici) was grown in liquid medium containing different concentrations of the compound. Viridiflorol, purchased by BOC Sciences (NY, USA), was initially diluted in methanol to a stock solution of $10 \mathrm{mg} / \mathrm{mL}$. The stock solution was used to prepare the working solutions, which contained either viridiflorol in concentrations of 500,1000, 2000 or $5000 \mu \mathrm{g} / \mathrm{mL}$, or methanol in the respective concentrations that served as control. In the wells of a 96-well microtiter plate, $25 \mu \mathrm{L}$ of each working solution and $225 \mu \mathrm{L}$ Potato Dextrose Broth (PDB) were added, ending up to the test concentrations of 50,100, 200 or $500 \mu \mathrm{g} / \mathrm{mL}$ viridiflorol or methanol. Hygromycin $(400 \mu \mathrm{g} / \mathrm{mL})$ was added in some wells instead of viridiflorol or methanol, as an antifungal drug that inhibits growth of the respective pathogens. The wells were inoculated with spores from C. truncatum isolate CP2304 (4000 spores) from the fungal collection in Copenhagen. The plate was incubated on a shaker $(100 \mathrm{rpm})$ for 6 days at room temperature and pictures were taken to identify fungal growth. Each treatment was performed in four replicates and the whole assay was done twice.

\subsection{Statistical Analysis}

The data from SiTPS relative expression was subjected to a $t$-test in order to compare pairwise gene expression levels between the two different growth conditions of $S$. indica (in tomato roots and on synthetic medium). Colonization rates of different $S$. indica strains represent continuous variables and were analyzed by analysis of variance, assuming a normal distribution (one-way ANOVA). For all the statistical tests performed, hypotheses were rejected at $p<0.05$ and all data were analyzed in R-Studio ( $\mathrm{R}$ version 3.4.1, https: //cran.r-project.org/bin/windows/base/old/3.4.1/).

\section{Results}

\subsection{SiTPS Belongs to Clade I of Basidiomycota STSs}

A phylogenetic tree containing previously characterized basidiomycete STSs (SiTPS included) $[3,4,6,8,12,14]$ was constructed and it showed that the specific enzymes are grouped into four distinct STS clades (Figure 2), also observed previously [3,11]. SiTPS 
was found in Clade I, which includes enzymes that catalyze formation of sesquiterpenoids through an initial C1-C10 closure of E,E-FPP (Figure 1).

An additional phylogenetic analysis was also conducted and included a selection of proteins, closely related to the S. indica STS (Supplementary Figure S1). The specific tree showed that SiTPS was grouped together with putative terpene synthases from other Serendipita species. In addition, the Serendipita sequences displayed close relation to a protein belonging to the lichen Cladonia uncialis.

\subsection{SiTPS Is Induced during Root-Colonization}

Expression of SiTPS was studied under two different growth conditions. Relative expression of SiTPS was quantified in fungal biomass from 14-day-old S. indica colonies, grown on complete medium $(\mathrm{CM})$ agar plates and compared to expression in S. indicacolonized tomato roots (11 days post inoculation, dpi) (Figure 3). Gene expression was significantly upregulated by 3 -fold when $S$. indica was growing in planta in comparison to the control samples.

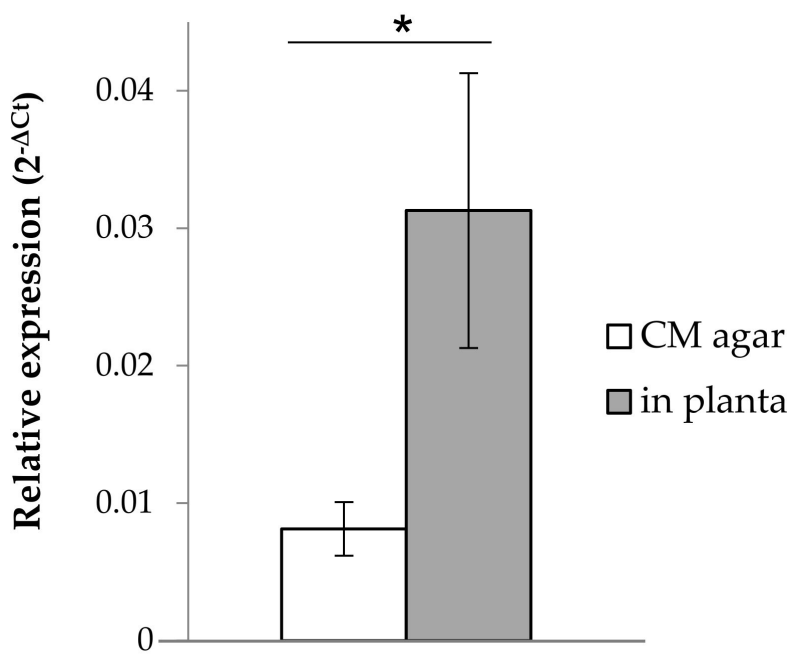

Figure 3. Relative expression of SiTPS when S. indica is grown for 14 days on complete medium (CM) agar plates compared to $S$. indica colonizing tomato roots (11 days post inoculation, dpi). Relative expression under both conditions was normalized using SiGAPDH (GenBank: FJ810523.1) expression levels and calculated with the $2^{-\Delta C t}$ method $[39,40]$. Error bars represent the standard error of the mean $(n=4)$. The asterisk $\left({ }^{*}\right)$ indicates a significant difference between the two conditions $(t$-test in R-studio, $\left.{ }^{*} p \leq 0.05\right)$.

\subsection{SiTPS Encodes for a Viridiflorol Synthase}

The biochemical activity of SiTPS was elucidated by using an in vitro and in vivo heterologous expression system (Figure 4). In the in vitro assays, the purified SiTPS, heterologously produced in E. coli cultures, was incubated with three terpene substrates (geranyl diphosphate- GPP, E,E-FPP and geranylgeranyl diphosphate- E,E,E-GGPP). Hexane extracts showed activity only when SiTPS was incubated with E,E-FPP (Supplementary Figure S3).

To validate results from the in vitro assays, an E. coli-based in vivo system was used as well. GC-MS analysis of hexane extracts from the bacterial culture co-expressing SiTPS with genes necessary for $E, E$-FPP production showed a number of peaks that were absent in the extract derived from the E,E-FPP-producing culture without SiTPS. The main product, matching the product from the in vitro assays in retention time and mass spectrum, showed closest matches to the sesquiterpene isomers viridiflorol and ledol in the NIST17 mass spectra database. Comparison with the authentic standard identified the product as viridiflorol (Figure 4). Based on the phylogenetic position of SiTPS (Figure 2) and the 
functional characterization of the enzyme (Figure 4), a putative cyclization mechanism for viridiflorol by SiTPS was proposed (Figure 5).
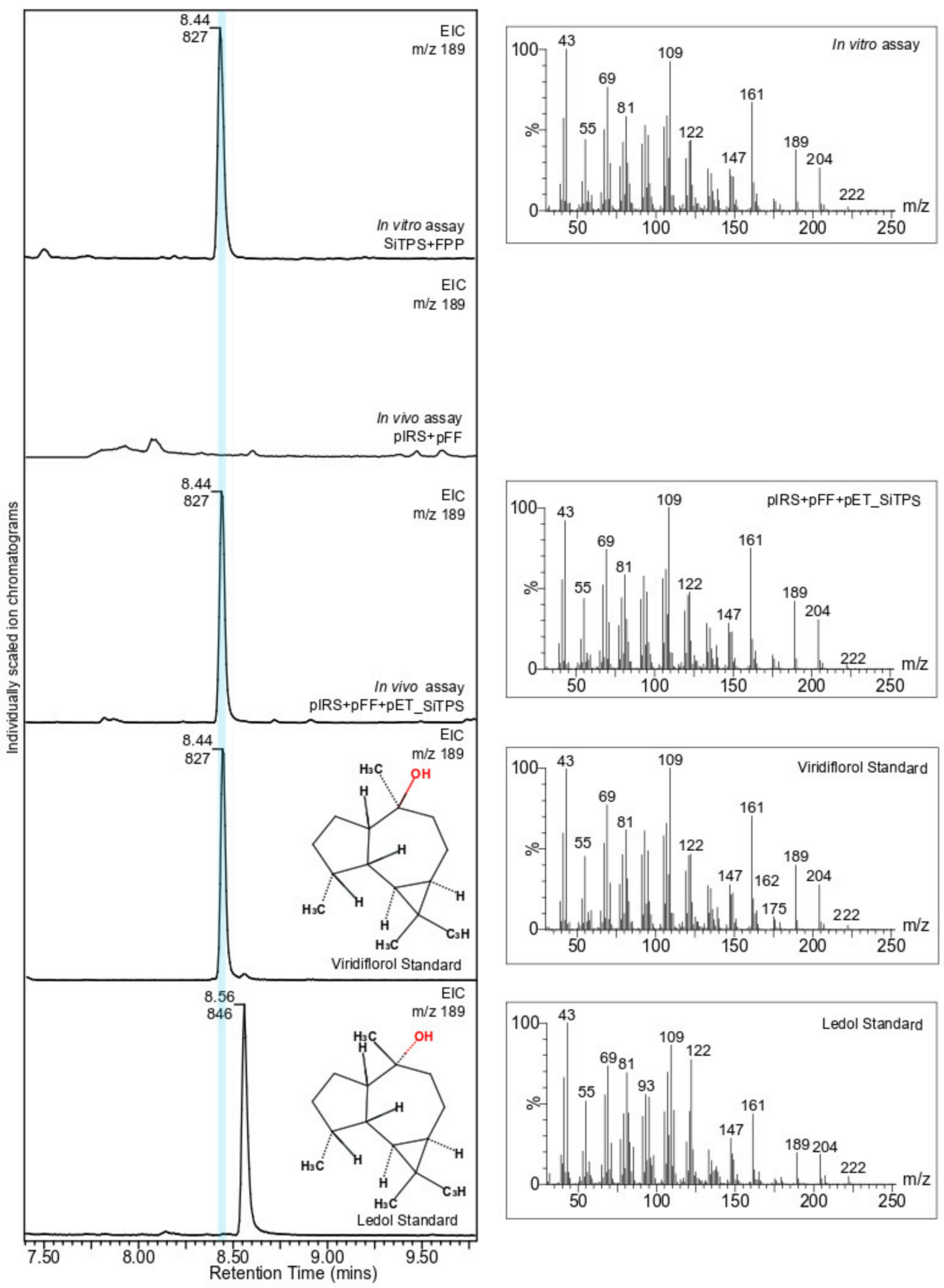

Figure 4. In vivo and in vitro characterization of SiTPS. GC-MS of hexane extracts from the in vitro assay in which the purified SiTPS was incubated with the substrate FPP (E,E-FPP) and from the in vivo assay with E. coli strains transformed with the plasmids pIRS, pFF and pET_SiTPS. An E. coli strain carrying only the pIRS and pFF plasmids was used as control. Analytical standards of viridiflorol and ledol were used to identify the produced compound. The mass spectra of the produced compounds and the analytical standards are given in the right hand panels. 


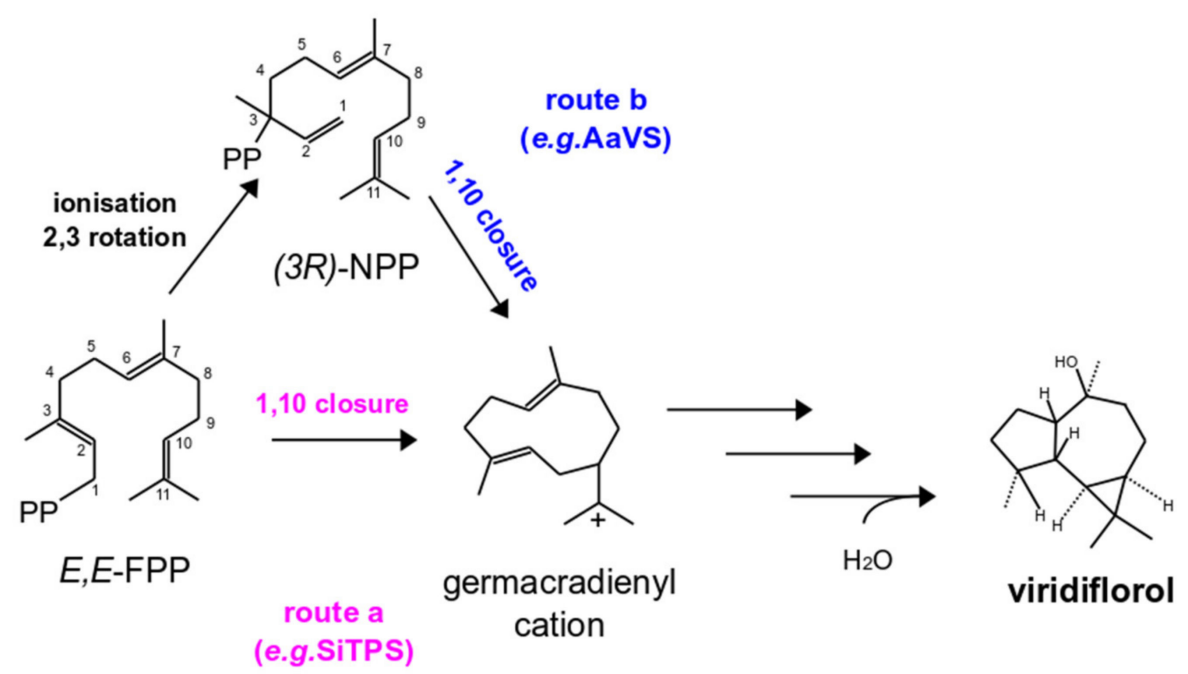

Figure 5. Proposed biosynthetic pathway leading to the production of viridiflorol. Viridiflorol biosynthesis starts with a 1,10-closure of either E,E-FPP (route a-Clade I, e.g., SiTPS) or (3R)-NPP (route b-Clade II, e.g., AaVS) to form a germacradienyl cation (E,E or $Z, E$, respectively). Two cyclization events (e.g., 1,11 and 2,6 closure) and additional reactions (e.g., addition of a molecule of water) result to formation of viridiflorol.

\subsection{Role of SiTPS during S. indica-Colonization of Tomato Roots}

Even though SiTPS was shown to express a functional viridiflorol synthase in E. coli expression systems, no terpenoids have been detected previously in S. indica cultures [48]. In addition, data showing SiTPS upregulation in fungal tissues associated with tomato roots (Figure 3) suggested that SiTPS products might play a role during plant colonization. To investigate the role of SiTPS in root colonization, S. indica mutants over-expressing SiTPS were designed. According to the antiSMASH analysis performed on the S. indica genome, SiTPS is a stand-alone gene and none of the genes in genomic proximity is related to terpene biosynthesis (Supplementary Figure S2). Based on that, we hypothesized that overexpressing SiTPS would have an accumulative effect on the amount of compounds produced.

After protoplast transformation, the regenerative clones were screened for having all four mating type genes (heterokaryotes) (Supplementary Figure S5A) and one SiTPSoverexpressing transformant (ovII) was selected and checked for SiTPS expression (Supplementary Figure S5B). The ovII strain was used in time-course colonization experiments to evaluate its ability to colonize plant roots. An S. indica-transformant carrying the empty vector (control treatment-evV) and the wild type $S$. indica were also used in this colonization study.

The ratio of fungal DNA to plant DNA was used as a measurement of the colonization ability of each $S$. indica strain. The colonization ratio was estimated in colonized roots at 2 and $11 \mathrm{dpi}$, but no difference was observed in the colonization ability between the over-expressing and the empty vector-carrying transformants at the selected time-points. No difference was observed in colonization ability between $S$. indica transformants and the wild type either (Table 1).

\subsection{Viridiflorol Has Antifungal Properties}

To study whether SiTPS is involved in a fungal defense mechanism, we performed an in vitro growth assay using viridiflorol, the main terpene produced by SiTPS. Spores from the plant pathogen Colletotrichum truncatum (syn. Colletotrichum capsici) isolate CP2304 were added in the wells of a microtiter plate, containing liquid medium supplemented with viridiflorol in different concentrations. The compound inhibited germination of spores and consequently growth of $C$. truncatum at a concentration of $100 \mu \mathrm{g} / \mathrm{mL}$ and higher, whereas the respective methanol controls did not affect at all fungal growth (Figure 6). 
Table 1. Colonization of tomato roots by $S$. indica wild type (wt), the empty vector-carrying (evV) and the SiTPS-overexpressing (ovII) mutants. The colonization ability of each strain was estimated using the ratio of fungal DNA (DNAf) to plant DNA (DNAp) at 2 and 11 days post inoculation (dpi). No statistical differences were observed in between the different treatments (one-way ANOVA in R-studio). Standard error of the mean (SEM) is also presented $(n=3)$.

\begin{tabular}{ccc}
\hline S. indica Strain & $\begin{array}{c}\text { 2 dpi } \\
\text { DNAf/DNAp } \pm \text { SEM }\end{array}$ & $\begin{array}{c}\text { 11 dpi } \\
\text { DNAf/DNAp } \pm \text { SEM }\end{array}$ \\
\hline wt & $0.0044 \pm 0.0003$ & $0.0324 \pm 0.0026$ \\
ovV & $0.0052 \pm 0.0001$ & $0.0468 \pm 0.0102$ \\
ovII & $0.0054 \pm 0.0008$ & $0.0301 \pm 0.0040$ \\
\hline
\end{tabular}

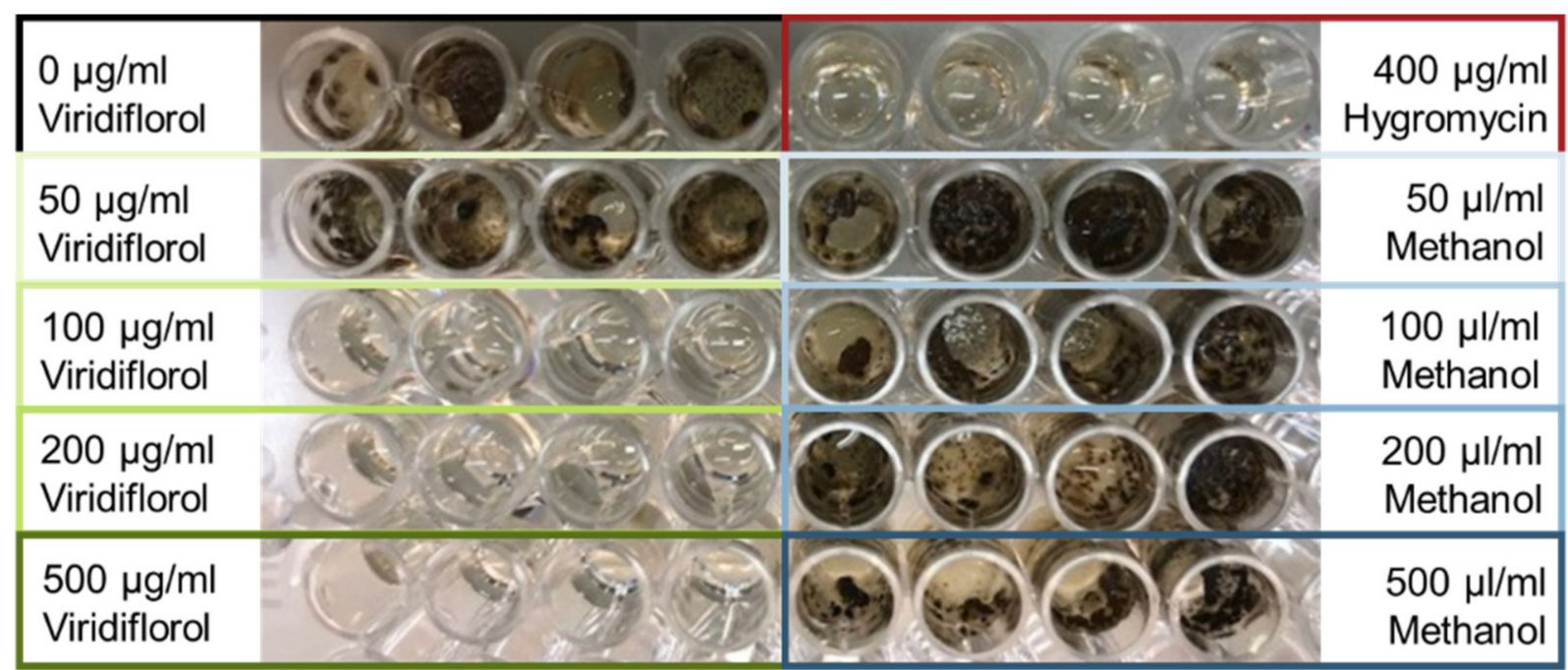

Figure 6. Microtiter plate wells containing PDB supplemented with viridiflorol, methanol or hygromycin and inoculated with 4000 spores of $C$. truncatum. Each treatment was performed in four replicates.

\section{Discussion}

\subsection{S. indica Possesses a Viridiflorol Synthase}

The in vitro and in vivo characterization assays showed that SiTPS accepts E,E-FPP to produce a mix of sesquiterpenoids with the main product identified as viridiflorol. Viridiflorol is a rare sesquiterpenoid with a 7/5/3 tricyclic scaffold belonging to the group of aromadendranes, which are terpenoids with a characteristic skeleton of a dimethyl cyclopropane ring fused to a hydroazulene ring system [49], usually used in fragrance production [50].

During sesquiterpenoid synthesis, FPP cyclization can occur either with the closure of $E, E$-FPP or its isomer, (3R)-NPP. A mechanism for the formation of viridiflorol was previously proposed, based on quantum chemical calculations, starting with the cyclization of E,E-FPP by a ring closure of C1 and C10 [51]. Phylogenetic analysis showing that SiTPS belongs to Clade I (Figure 2), together with enzymes that perform 1,10 cyclization of $E, E$ FPP, supports that activity of SiTPS proceeds through route a (Figure 5). On the contrary, another viridiflorol synthase isolated from the black poplar mushroom, Cyclocybe aegerita (syn. Agrocybe aegerita) [14], named AaVS, was placed in Clade II, together with enzymes that perform 1,10 cyclization of (3R)-NPP, indicating that biosynthesis of viridiflorol can actually occur through both routes (Figure 5).

Viridiflorol has also been detected in extracts of many plant species belonging to the families Myrtaceae [52] and Lamiaceae [53,54], but until now only two viridiflorol synthases of plant origin have been identified [52]. The specific compound has also been encountered as a minor product in fungal extracts [55,56] and after AaVS [14], SiTPS is the second fungal enzyme identified and experimentally characterized as a viridiflorol synthase. 


\subsection{Overexpression of SiTPS Does Not Affect S. indica Colonization Ability}

SiTPS was found to be upregulated at $11 \mathrm{dpi}$ in colonized tomato roots, when its expression was compared to that from a mature fungal colony grown on synthetic medium. However, gene expression data generated from a microarray assay performed on $S$. indicacolonized barley roots showed that SiTPS expression is induced in planta but at different timepoints [57]. In details, when we re-analyzed the data from barley roots, transcripts of SiTPS were found to accumulate specifically at the very early stages of colonization, around 36 to $48 \mathrm{~h}$ post inoculation (hpi), both in living and dead colonized roots, when compared to growth on synthetic medium. However, a similar expression pattern was not observed during later stages ( $5 \mathrm{dpi})$. This observation could possibly suggest that the gene is more important at the very early stages of the interaction, during the pre-penetration phase, or that differences in SiTPS expression evaded detection by the specific method. Another observation in this study was that when dead and living barley roots were compared, accumulation of SiTPS transcripts was higher in living roots, indicating that $S$. indica activates SiTPS when association with living tissues takes place.

Our SiTPS expression data and former literature led us to hypothesize that SiTPS can be involved in colonization of plant roots by $S$. indica. Hence, we established a root-colonization assay, where tomato seedlings were inoculated with either an SiTPSoverexpressing mutant or control strains and the ratio between fungal to plant DNA was used to evaluate fungal colonization ability. The SiTPS-overexpressing mutant appeared to colonize tomato roots to the same extent as the empty vector-carrying transformant and the wild type $S$. indica, showing that overexpression of the $S$. indica viridiflorol synthase gene does not influence fungal colonization ability at the specific time-points and in our experimental set-up. In another study, the colonization ability of Trichoderma virens, an endophytic fungus able to produce several volatile terpene compounds, was compared with this of deletion mutants and other Trichoderma species that lack the terpene synthase gene responsible for the synthesis of these metabolites [58]. Similar to our findings, the specific study showed that the ability to produce terpenes did not correlate with increased fungal colonization ability, since there was no significant difference between colonization ratio of the fungal strains used.

However, these results do not exclude that the products of SiTPS could play another role in planta. For example, fungal sesquiterpenoids could act as signaling or defense molecules against other root-residing microorganisms. In fact, according to a whole transcriptome study performed on colonized roots of barley plants, a putative terpene synthase gene from the orchid mycorrhizal fungus Serendipita vermifera ssp. bescii, was upregulated significantly only when another fungus (the pathogen Bipolaris sorokiniana) was colonizing the plant roots [59].

\subsection{Viridiflorol Could Serve as a Defense Compound against Other Plant-Associated Fungi}

It has been shown repeatedly that volatile organic compounds, including volatile terpenoids, mediate communication between plants and microorganisms [60]. Several plant terpenoids, such as $\alpha$ - and $\beta$-pinene or abietic acid, have been considered to be positively involved in the development of ectomycorrhizal associations, mainly during the pre-symbiotic phase $[61,62]$. On the other hand, little is known about fungal terpenoids and their role in endophytism and to our knowledge, there is no direct evidence that they facilitate establishment of plant-endophytic interactions. Terpenoids produced by fungi are considered to be implicated mostly in defense against antagonists or in signaling with other microorganisms $[60,63]$. Therefore, we redirected the focus of our study into exploring the potential of viridiflorol as a defense compound. The in vitro growth assay showed that high concentrations of viridiflorol (>100 $\mu \mathrm{g} / \mathrm{mL}$ ) could successfully inhibit the germination and consequently the growth of the phytopathogenic fungus $C$. truncatum. Previous studies have also shown that viridiflorol has weak to moderate anti-inflammatory and antimicrobial activity $[49,64-66]$, suggesting that the ability to produce this compound could provide 
S. indica with an advantage when growing in a more competitive environment, where several rhizospheral microorganisms are fighting for a niche within the plant tissue.

In our case, antagonism assays and co-cultures including $S$. indica wild type or mutants and other plant-associated microorganisms might further support our hypothesis about viridiflorol being implicated in defense. Additionally, in planta experiments with knockout $S$. indica mutants and other microbial competitors could provide an even more realistic image regarding the actual role of SiTPS and sesquiterpenes during a tripartite association between a plant, a pathogen, and a beneficial symbiont. Identifying the role of endophytic terpenoids during symbiotic associations will provide a more in-depth understanding of these complex interactions and their effect in the surrounding environment, opening up new opportunities for their application in agriculture.

\section{Patents}

The authors have filed the patent application "Method for producing the sesquiterpene viridiflorol with a fungal enzyme" describing the function of the $S$. indica terpene synthase (U.S. Patent Application Serial No.: 62/899,391).

Supplementary Materials: The following are available online at https:/ /www.mdpi.com/article/10 .3390/biom11060898/s1, Figure S1: Phylogenetic analysis of SiTPS and related sequences, Figure S2: Terpene biosynthetic clusters of SiTPS and SvTPS in S. indica and S. vermifera, Figure S3: GCMS chromatograms (total ion count, TIC) from hexane extracts of the in vitro enzyme assays of SiTPS with GPP, FPP (E,E-FPP) and GGPP (E,E,E-GPP) (IS, Internal Standard), Figure S4: The plasmid K167_PromFCGB1_SiTPS_His used for making the SiTPS-overexpressing mutants, Figure S5: S. indica transformants used in colonization studies were selected based on: A. their mating type; and B. SiTPS relative expression in transformants grown on CM agar plates for 14 days, Figure S6: Multiple Sequence Alignment (MSA) of Basidiomycota STSs, colored according to the confidence score generated from GUIDANCE2 Server (CLUSTALW), Figure S7: Multiple Sequence Alignment (MSA) of similar to SiTPS proteins, colored according to the confidence score generated from GUIDANCE2 Server (MAFFT), Table S1: Primer list.

Author Contributions: Conceptualization, F.N. and B.H.; methodology, F.N., B.H. and W.W.B.; software, S.R.J.; validation, formal analysis, investigation, F.N., W.W.B. and S.R.J.; resources, B.H. and D.B.C.; writing — original draft preparation, writing — review and editing, all authors; visualization, F.N., W.W.B. and B.J; supervision, B.H., D.B.C., H.J.L.J. and B.J.; funding acquisition, B.H., and D.B.C. All authors have read and agreed to the published version of the manuscript.

Funding: This work was supported by the Michigan State University Strategic Partnership Grant program ("Evolutionary-Driven Genome Mining of Plant Biosynthetic Pathways" and "Plant-inspired Chemical Diversity", B.H.). B.H. gratefully acknowledges the U.S. Department of Energy-Great Lakes Bioenergy Research Center Cooperative Agreement DE-SC0018409, start-up funding from the Department of Molecular Biology and Biochemistry and support by the USDA National Institute of Food and Agriculture, HATCH project MICL02454. B.H. is in part supported by the National Science Foundation under Grant Number 1737898. Any opinions, findings, and conclusions or recommendations expressed in this material are those of the author(s) and do not necessarily reflect the views of the National Science Foundation. This project has also received funding from the European Union's Horizon 2020 research and innovation programme under the Marie SkłodowskaCurie grant agreement No. 676480. This material reflects only the authors' view and the Research Executive Agency is not responsible for any use that may be made of the information it contains.

Institutional Review Board Statement: Not applicable.

Informed Consent Statement: Not applicable.

Data Availability Statement: Not applicable.

Acknowledgments: We would like to thank Philipp Franken (Friedrich-Schiller University, Germany) for providing the Serendipita indica DSM 11827 isolate, Frank Takken (University of Amsterdam, the Netherlands) for the Solanum lycopersicum cv. Moneymaker seeds, as well as Alga Zuccaro, Stephan Wawra and Heidi Widmer (University of Cologne, Germany) for kindly providing the K167 vector 
and advice on the S. indica transformation procedure. Also thanks to the facilities at Michigan State University, including the Mass Spectrometry and Metabolomics Core.

Conflicts of Interest: The authors have filed a provisional patent application "Method for producing the sesquiterpene viridiflorol with a fungal enzyme" describing the function of the $S$. indica terpene synthase (U.S. Patent Application Serial No.: 62/899,391).

\section{References}

1. Gershenzon, J.; Dudareva, N. The function of terpene natural products in the natural world. Nat. Chem. Biol. 2007, 3, 408-414. [CrossRef]

2. Blackwell, M. The Fungi: 1, 2, 3 . . 5.1 million species? Am. J. Bot. 2011, 98, 426-438. [CrossRef] [PubMed]

3. Wawrzyn, G.T.; Quin, M.B.; Choudhary, S.; López-Gallego, F.; Schmidt-Dannert, C. Draft genome of Omphalotus olearius provides a predictive framework for sesquiterpenoid natural product biosynthesis in basidiomycota. Chem. Biol. 2012, 19, 772-783. [CrossRef] [PubMed]

4. Agger, S.; Lopez-Gallego, F.; Schmidt-Dannert, C. Diversity of sesquiterpene synthases in the basidiomycete Coprinus cinereus. Mol. Microbiol. 2009, 72, 1181-1195. [CrossRef] [PubMed]

5. Lopez-Gallego, F.; Wawrzyn, G.; Schmidt-Dannert, C. Selectivity of fungal sesquiterpene synthases: Role of the active site's H-1 $\alpha$ loop in catalysis. Appl. Environ. Microbiol. 2010, 76, 7723-7733. [CrossRef]

6. Lopez-Gallego, F.; Agger, S.A.; Abate-Pella, D.; Distefano, M.D.; Schmidt-Dannert, C. Sesquiterpene synthases Cop4 and Cop6 from Coprinus cinereus: Catalytic promiscuity and cyclization of farnesyl pyrophosphate geometric isomers. ChemBioChem 2010, 11, 1093-1106. [CrossRef] [PubMed]

7. Wawrzyn, G.T.; Bloch, S.E.; Schmidt-Dannert, C. Discovery and characterization of terpenoid biosynthetic pathways of fungi. Methods Enzymol. 2012, 515, 83-105. [CrossRef] [PubMed]

8. Flynn, C.M.; Schmidt-Dannert, C. Sesquiterpene synthase-3-hydroxy-3-methylglutaryl coenzyme A synthase fusion protein responsible for hirsutene biosynthesis in Stereum hirsutum. Appl. Environ. Microbiol. 2018, 84, 1-18. [CrossRef] [PubMed]

9. Schueffler, A.; Anke, T. Fungal natural products in research and development. Nat. Prod. Rep. 2014, 31, 1425-1448. [CrossRef]

10. Christianson, D.W. Structural biology and chemistry of the terpenoid cyclases. Chem. Rev. 2006, 106, 3412-3442. [CrossRef]

11. Quin, M.B.; Flynn, C.M.; Wawrzyn, G.T.; Choudhary, S.; Schmidt-Dannert, C. Mushroom hunting by using bioinformatics: Application of a predictive framework facilitates the selective identification of sesquiterpene synthases in Basidiomycota. ChemBioChem 2013, 14, 2480-2491. [CrossRef] [PubMed]

12. Quin, M.B.; Michel, S.N.; Schmidt-Dannert, C. Moonlighting metals: Insights into regulation of cyclization pathways in fungal $\Delta 6$-protoilludene sesquiterpene synthases. ChemBioChem 2015, 16, 2191-2199. [CrossRef] [PubMed]

13. Engels, B.; Heinig, U.; Grothe, T.; Stadler, M.; Jennewein, S. Cloning and characterization of an Armillaria gallica cDNA encoding protoilludene synthase, which catalyzes the first committed step in the synthesis of antimicrobial melleolides. J. Biol. Chem. 2011, 286, 6871-6878. [CrossRef] [PubMed]

14. Shukal, S.; Chen, X.; Zhang, C. Systematic engineering for high-yield production of viridiflorol and amorphadiene in auxotrophic Escherichia coli. Metab. Eng. 2019, 55, 170-178. [CrossRef] [PubMed]

15. Flynn, C.M.; Broz, K.; Jonkers, W.; Schmidt-Dannert, C.; Kistler, H.C. Expression of the Fusarium graminearum terpenome and involvement of the endoplasmic reticulum-derived toxisome. Fungal Genet. Biol. 2019, 124, 78-87. [CrossRef] [PubMed]

16. Vadassery, J.; Ritter, C.; Venus, Y.; Camehl, I.; Varma, A.; Shahollari, B.; Novák, O.; Strnad, M.; Ludwig-Müller, J.; Oelmüller, R. The role of auxins and cytokinins in the mutualistic interaction between Arabidopsis and Piriformospora indica. Mol. Plant-Microbe Interact. 2008, 21, 1371-1383. [CrossRef] [PubMed]

17. Akum, F.N.; Steinbrenner, J.; Biedenkopf, D.; Imani, J.; Kogel, K.-H. The Piriformospora indica effector PIIN_08944 promotes the mutualistic Sebacinalean symbiosis. Front. Plant Sci. 2015, 6, 1-12. [CrossRef] [PubMed]

18. Nizam, S.; Qiang, X.; Wawra, S.; Nostadt, R.; Getzke, F.; Schwanke, F.; Dreyer, I.; Langen, G.; Zuccaro, A. Serendipita indica E5' NT modulates extracellular nucleotide levels in the plant apoplast and affects fungal colonization. EMBO Rep. 2019, 20, 1-17. [CrossRef]

19. Varma, A.; Verma, S.; Sudha, S.; Butehorn, B.; Franken, P. Piriformospora indica, a cultivable plant-growth-promoting root endophyte. Appl. Environ. Microbiol. 1999, 65, 2741-2744. [CrossRef]

20. Waller, F.; Achatz, B.; Baltruschat, H.; Fodor, J.; Becker, K.; Fischer, M.; Heier, T.; Huckelhoven, R.; Neumann, C.; von Wettstein, D.; et al. The endophytic fungus Piriformospora indica reprograms barley to salt-stress tolerance, disease resistance, and higher yield. Proc. Natl. Acad. Sci. USA 2005, 102, 13386-13391. [CrossRef]

21. Lee, Y.-C.; Johnson, J.M.; Chien, C.-T.; Sun, C.; Cai, D.; Lou, B.; Oelmüller, R.; Yeh, K.-W. Growth promotion of chinese cabbage and Arabidopsis by Piriformospora indica is not stimulated by mycelium-synthesized auxin. Mol. Plant-Microbe Interact. 2011, 24, 421-431. [CrossRef] [PubMed]

22. Bajaj, R.; Huang, Y.; Gebrechristos, S.; Mikolajczyk, B.; Brown, H.; Prasad, R.; Varma, A.; Bushley, K.E. Transcriptional responses of soybean roots to colonization with the root endophytic fungus Piriformospora indica reveals altered phenylpropanoid and secondary metabolism. Sci. Rep. 2018, 8, 10227. [CrossRef] [PubMed]

23. Liu, B.; Liu, X.; Liu, F.; Ma, H.; Ma, B.; Zhang, W.; Peng, L. Growth improvement of Lolium multiflorum Lam. induced by seed inoculation with fungus suspension of Xerocomus badius and Serendipita indica. AMB Express 2019, 9, 145. [CrossRef] 
24. Stein, E.; Molitor, A.; Kogel, K.H.; Waller, F. Systemic resistance in Arabidopsis conferred by the mycorrhizal fungus Piriformospora indica requires jasmonic acid signaling and the cytoplasmic function of NPR1. Plant Cell Physiol. 2008, 49, 1747-1751. [CrossRef] [PubMed]

25. Fakhro, A.; Andrade-Linares, D.R.; von Bargen, S.; Bandte, M.; Büttner, C.; Grosch, R.; Schwarz, D.; Franken, P. Impact of Piriformospora indica on tomato growth and on interaction with fungal and viral pathogens. Mycorrhiza 2010, 20, 191-200. [CrossRef] [PubMed]

26. Jacobs, S.; Zechmann, B.; Molitor, A.; Trujillo, M.; Petutschnig, E.; Lipka, V.; Kogel, K.-H.; Schafer, P. Broad-spectrum suppression of innate immunity is required for colonization of Arabidopsis roots by the fungus Piriformospora indica. Plant Physiol. 2011, 156, 726-740. [CrossRef]

27. Cheng, C.; Li, D.; Qi, Q.; Sun, X.; Anue, M.R.; David, B.M.; Zhang, Y.; Hao, X.; Zhang, Z.; Lai, Z. The root endophytic fungus Serendipita indica improves resistance of banana to Fusarium oxysporum f. sp. cubense tropical race 4. Eur. J. Plant Pathol. 2020, 156, 87-100. [CrossRef]

28. Sun, C.; Johnson, J.M.; Cai, D.; Sherameti, I.; Oelmüller, R.; Lou, B. Piriformospora indica confers drought tolerance in chinese cabbage leaves by stimulating antioxidant enzymes, the expression of drought-related genes and the plastid-localized CAS protein. J. Plant Physiol. 2010, 167, 1009-1017. [CrossRef]

29. Xu, L.; Wang, A.; Wang, J.; Wei, Q.; Zhang, W. Piriformospora indica confers drought tolerance on Zea mays L. through enhancement of antioxidant activity and expression of drought-related genes. Crop J. 2017, 5, 251-258. [CrossRef]

30. Schäfer, P.; Pfiffi, S.; Voll, L.M.; Zajic, D.; Chandler, P.M.; Waller, F.; Scholz, U.; Pons-Kühnemann, J.; Sonnewald, S.; Sonnewald, U.; et al. Manipulation of plant innate immunity and gibberellin as factor of compatibility in the mutualistic association of barley roots with Piriformospora indica. Plant J. 2009, 59, 461-474. [CrossRef]

31. Lahrmann, U.; Zuccaro, A. Opprimo ergo sum - Evasion and suppression in the root endophytic fungus Piriformospora indica. Mol. Plant-Microbe Interact. 2012, 25, 727-737. [CrossRef] [PubMed]

32. Sirrenberg, A.; Göbel, C.; Grond, S.; Czempinski, N.; Ratzinger, A.; Karlovsky, P.; Santos, P.; Feussner, I.; Pawlowski, K. Piriformospora indica affects plant growth by auxin production. Physiol. Plant. 2007, 131, 581-589. [CrossRef] [PubMed]

33. Hilbert, M.; Voll, L.M.; Ding, Y.; Hofmann, J.; Sharma, M.; Zuccaro, A. Indole derivative production by the root endophyte Piriformospora indica is not required for growth promotion but for biotrophic colonization of barley roots. New Phytol. 2012, 196, 520-534. [CrossRef] [PubMed]

34. Das, A.; Kamal, S.; Shakil, N.A.; Sherameti, I.; Oelmüller, R.; Dua, M.; Tuteja, N.; Johri, A.K.; Varma, A. The root endophyte fungus Piriformospora indica leads to early flowering, higher biomass and altered secondary metabolites of the medicinal plant, Coleus forskohlii. Plant Signal. Behav. 2012, 7, 103-112. [CrossRef]

35. Satheesan, J.; Narayanan, A.K.; Sakunthala, M. Induction of root colonization by Piriformospora indica leads to enhanced asiaticoside production in Centella asiatica. Mycorrhiza 2012, 22, 195-202. [CrossRef] [PubMed]

36. Sharma, G.; Agrawal, V. Marked enhancement in the artemisinin content and biomass productivity in Artemisia annua L. shoots co-cultivated with Piriformospora indica. World J. Microbiol. Biotechnol. 2013, 29, 1133-1138. [CrossRef] [PubMed]

37. Pham, G.H.; Singh, A.; Malla, R.; Kumari, R.; Prasad, R.; Sachdev, M.; Rexer, K.-H.; Kost, G.; Luis, P.; Kaldorf, M.; et al. Interaction of Piriformospora indica with diverse microorganisms and plants. In Plant Surface Microbiology; Varma, A., Abbott, L., Werner, D., Hampp, R., Eds.; Springer: Berlin/Heidelberg, Germany, 2008; pp. 237-265. ISBN 978-3-540-74051-3.

38. Kumar, S.; Stecher, G.; Li, M.; Knyaz, C.; Tamura, K. MEGA X: Molecular evolutionary genetics analysis across computing platforms. Mol. Biol. Evol. 2018, 35, 1547-1549. [CrossRef]

39. Blin, K.; Shaw, S.; Steinke, K.; Villebro, R.; Ziemert, N.; Lee, S.Y.; Medema, M.H.; Weber, T. antiSMASH 5.0: Updates to the secondary metabolite genome mining pipeline. Nucleic Acids Res. 2019, 47, W81-W87. [CrossRef] [PubMed]

40. Livak, K.J.; Schmittgen, T.D. Analysis of relative gene expression data using real-time quantitative PCR and the $2^{-\Delta \Delta C T}$ method. Methods 2001, 25, 402-408. [CrossRef]

41. Schmittgen, T.D.; Livak, K.J. Analyzing real-time PCR data by the comparative CT method. Nat. Protoc. 2008, 3, 1101-1108. [CrossRef]

42. Johnson, S.R.; Bhat, W.W.; Sadre, R.; Miller, G.P.; Garcia, A.S.; Hamberger, B. Promiscuous terpene synthases from Prunella vulgaris highlight the importance of substrate and compartment switching in terpene synthase evolution. New Phytol. 2019, 223, 323-335. [CrossRef]

43. Morrone, D.; Lowry, L.; Determan, M.K.; Hershey, D.M.; Xu, M.; Peters, R.J. Increasing diterpene yield with a modular metabolic engineering system in E. coli: Comparison of MEV and MEP isoprenoid precursor pathway engineering. Appl. Microbiol. Biotechnol. 2010, 85, 1893-1906. [CrossRef]

44. Cyr, A.; Wilderman, P.R.; Determan, M.; Peters, R.J. A modular approach for facile biosynthesis of labdane-related diterpenes. J. Am. Chem. Soc. 2007, 129, 6684-6685. [CrossRef] [PubMed]

45. Johnson, S.R.; Bhat, W.W.; Bibik, J.; Turmo, A.; Hamberger, B.; Hamberger, B. A database-driven approach identifies additional diterpene synthase activities in the mint family (Lamiaceae). J. Biol. Chem. 2019, 294, 1349-1362. [CrossRef] [PubMed]

46. Wawra, S.; Fesel, P.; Widmer, H.; Timm, M.; Seibel, J.; Leson, L.; Kesseler, L.; Nostadt, R.; Hilbert, M.; Langen, G.; et al. The fungal-specific $\beta$-glucan-binding lectin FGB1 alters cell-wall composition and suppresses glucan-triggered immunity in plants. Nat. Commun. 2016, 7, 13188. [CrossRef] [PubMed] 
47. Zuccaro, A.; Basiewicz, M.; Zurawska, M.; Biedenkopf, D.; Kogel, K.-H. Karyotype analysis, genome organization, and stable genetic transformation of the root colonizing fungus Piriformospora indica. Fungal Genet. Biol. 2009, 46, 543-550. [CrossRef] [PubMed]

48. Varma, A.; Sherameti, I.; Tripathi, S.; Prasad, R.; Das, A.; Sharma, M. Fungal Associations; Hock, B., Ed.; Springer: Berlin/Heidelberg, Germany, 2012; Volume 9, ISBN 978-3-642-30825-3.

49. Gijsen, H.J.M.; Stork, G.A.; De Groat, A.; De Waard, A.; Nistelrooy, J.G.M. Van The synthesis of mono- and dihydroxy aromadendrane starting from natural (+)-aromadendrene-III. Tetrahedron 1992, 48, 2465-2476. [CrossRef]

50. McAndrew, B.A. Fragrance Chemistry: The science of the sense of smell. Theimer, E.T., Ed.; Academic Press: New York, NY, USA, 2006; Volume 95, 1982. XIII, 635; ISBN 978-0-323-1386-04.

51. Hong, Y.J.; Tantillo, D.J. Is a 1,4-alkyl shift involved in the biosynthesis of ledol and viridiflorol? J. Org. Chem. 2017, 82, 3957-3959. [CrossRef] [PubMed]

52. Padovan, A.; Keszei, A.; Köllner, T.G.; Degenhardt, J.; Foley, W.J. The molecular basis of host plant selection in Melaleuca quinquenervia by a successful biological control agent. Phytochemistry 2010, 71, 1237-1244. [CrossRef]

53. Medjahed, F.; Merouane, A.; Saadi, A.; Bader, A.; Cioni, P.L.; Flamini, G. Chemical profile and antifungal potential of essential oils from leaves and flowers of Salvia algeriensis (Desf.): A comparative study. Chil. J. Agric. Res. 2016, 76, 195-200. [CrossRef]

54. Ramírez, J.; Gilardoni, G.; Ramón, E.; Tosi, S.; Picco, A.; Bicchi, C.; Vidari, G. Phytochemical study of the ecuadorian species Lepechinia mutica (Benth.) epling and high antifungal activity of carnosol against Pyricularia oryzae. Pharmaceuticals 2018, 11, 33 [CrossRef] [PubMed]

55. Meshram, V.; Saxena, S.; Kapoor, N. Muscodor strobelii, a new endophytic species from South India. Mycotaxon 2014, 128, 93-104. [CrossRef]

56. Wu, W.; Tran, W.; Taatjes, C.A.; Alonso-Gutierrez, J.; Lee, T.S.; Gladden, J.M. Rapid discovery and functional characterization of terpene synthases from four endophytic Xylariaceae. PLoS ONE 2016, 11, 1-19. [CrossRef] [PubMed]

57. Zuccaro, A.; Lahrmann, U.; Güldener, U.; Langen, G.; Pfiffi, S.; Biedenkopf, D.; Wong, P.; Samans, B.; Grimm, C.; Basiewicz, M.; et al. Endophytic life strategies decoded by genome and transcriptome analyses of the mutualistic root symbiont Piriformospora indica. PLoS Pathog. 2011, 7, 1-26. [CrossRef]

58. Crutcher, F.K.; Parich, A.; Schuhmacher, R.; Mukherjee, P.K.; Zeilinger, S.; Kenerley, C.M. A putative terpene cyclase, vir4, is responsible for the biosynthesis of volatile terpene compounds in the biocontrol fungus Trichoderma virens. Fungal Genet. Biol. 2013, 56, 67-77. [CrossRef]

59. Sarkar, D.; Rovenich, H.; Jeena, G.; Nizam, S.; Tissier, A.; Balcke, G.U.; Mahdi, L.K.; Bonkowski, M.; Langen, G.; Zuccaro, A. The inconspicuous gatekeeper: Endophytic Serendipita vermifera acts as extended plant protection barrier in the rhizosphere. New Phytol. 2019, 224, 886-901. [CrossRef]

60. Wenke, K.; Kai, M.; Piechulla, B. Belowground volatiles facilitate interactions between plant roots and soil organisms. Planta 2010, 231, 499-506. [CrossRef]

61. Fries, N.; Serck-Hanssen, K.; Dimberg, L.H.; Theander, O. Abietic acid, and activator of basidiospore germination in ectomycorrhizal species of the genus Suillus (Boletaceae). Exp. Mycol. 1987, 11, 360-363. [CrossRef]

62. Menotta, M.; Gioacchini, A.M.; Amicucci, A.; Buffalini, M.; Sisti, D.; Stocchi, V. Headspace solid-phase microextraction with gas chromatography and mass spectrometry in the investigation of volatile organic compounds in an ectomycorrhizae synthesis system. Rapid Commun. Mass Spectrom. 2004, 18, 206-210. [CrossRef]

63. Hynes, J.; Müller, C.T.; Jones, T.H.; Boddy, L. Changes in volatile production during the course of fungal mycelial interactions between Hypholoma fasciculare and Resinicium bicolor. J. Chem. Ecol. 2006, 33, 43-57. [CrossRef] [PubMed]

64. Scher, J.M.; Speakman, J.-B.; Zapp, J.; Becker, H. Bioactivity guided isolation of antifungal compounds from the liverwort Bazzania trilobata (L.) S.F. Gray. Phytochemistry 2004, 65, 2583-2588. [CrossRef] [PubMed]

65. Trevizan, L.N.F.; do Nascimento, K.F.; Santos, J.A.; Kassuya, C.A.L.; Cardoso, C.A.L.; Vieira, M.d.C.; Moreira, F.M.F.; Croda, J.; Formagio, A.S.N. Anti-inflammatory, antioxidant and anti-Mycobacterium tuberculosis activity of viridiflorol: The major constituent of Allophylus edulis. J. Ethnopharmacol. 2016, 192, 510-515. [CrossRef] [PubMed]

66. Furtado, F.; Borges, B.; Teixeira, T.; Garces, H.; Almeida Junior, L.; Alves, F.; Silva, C.; Fernandes Junior, A. Chemical composition and bioactivity of essential oil from Blepharocalyx salicifolius. Int. J. Mol. Sci. 2018, 19, 33. [CrossRef] [PubMed] 